\title{
Role of Electroencephalogram and Neuroimaging in First Afebrile Seizure in Children: A Retrospective Study
}

\author{
Shwetha.G ${ }^{1}$, SinchanaBhat ${ }^{2}$, Santosh T Soans ${ }^{3}$ \\ ${ }^{1}$ Post Graduate, Department of Pediatrics, AJ Institute of medical sciences, Kuntikana, Mangalore, ${ }^{2}$ Assistant Professor, Department of Pediatrics, AJ Institute of medical \\ sciences, Kuntikana, Mangalore, ${ }^{3}$ Professor and Head, Department of Pediatrics, AJ Institute of medical sciences, Kuntikana, Mangalore.
}

\section{Abstract}

Background: To evaluate the role of EEG and Magnetic resonance imaging (MRI) in first episode of unprovoked afebrile seizure in a child. Subjects and Methods: Data was collected retrospectively from case records of patients admitted with seizures during the period between January 2016 to December 2018. All children with first episode of unprovoked afebrile seizure (1-15 years of age) were included in the study. Results: Case records of 108 patients with first episode of unprovoked afebrile seizures were reviewed . Out of these , 65 patients were investigated with MRI and EEG.54 children (83.1\%)had generalized tonic clonic seizures(GTCS), 11 had partial seizures (16.9 \%) . EEG abnormalities were seen in 21 children, predominantly in GTCS type. The most common EEG abnormality observed was sharp and spike wave discharges .7 children $(10.7 \%$ ) had abnormal (MRI). The accuracy of MRI detecting the abnormality when EEG was abnormal was $33.3 \%$ (p $<0.05)$. Conclusion: This study illustrates that routine neuroimaging for all children with first episode of unprovoked afebrile seizures is gratuitous. Neuroimaging can be reserved for those patients with recurrence of seizures or those children with clinical findings suggestive of intracranial pathologies.

Keywords: Seizures, EEG, Afebrile, MRI, First episode.

Corresponding Author: Dr.Sinchana Bhat, Assistant Professor, Department of Paediatrics, AJ Institute of medical sciences , Kuntikana, Mangalore.

Received: March 2019

Accepted: March 2019

\section{Introduction}

It is estimated that about $10 \%$ of the population are known to have a seizure at some point in their lifetime. ${ }^{[1]}$ Also, it accounts for about $1 \%$ of visits to the emergency department with a high incidence among infants and young children. ${ }^{[2,3]}$ The first seizure may indicate an initial presentation of epilepsy or an underlying neurological disease.

The combination of seizure history, electroencephalography (EEG) and neuroimaging allows the clinician for the accurate diagnosis \& early management decisions regarding antiepileptic drug therapy and surgery and also facilitates patient counseling. Although EEG is recommended as a part of the neurodiagnostic evaluation of the child with an apparent first unprovoked seizure, ${ }^{[4,5]}$ the role of neuroimaging in these children is not well defined. In a few studies that have reviewed the yield of neuroimaging in children with unprovoked seizure, the prevalence of abnormalities ranged from $0 \%$ to $21 \%$. $^{[6-8]}$

Neuroimaging (MRI) is one of the useful tool to determine the etiological diagnosis of seizure. The purpose of emergency neuroimaging is to look for the intracranial pathology that requires immediate surgical intervention in children who presents with first episode of afebrile seizure. However, there is no standard recommendation or guidelines for neuroimaging in children with unprovoked seizure.

The American College of Emergency Physicians recommends neuroimaging for those younger than one year, those with cognitive or motor developmental delay, unexplained neurologic abnormalities, a history of focal seizures or findings on electroencephalography (EEG) that are incompatible with benign partial epilepsy of childhood or primary generalized epilepsy. ${ }^{[5]}$

We conducted this study to evaluate the role of EEG and neuroimaging in first episode afebrile seizure.

\section{Subjects and Methods}

This was a retrospective study done in the department of Paediatrics at AJ Institute of Medical Sciences, Mangalore. Data was collected from January 2016 to December 2018 using the G-health software system used for data storage of inpatients in our hospital. Individual case records were retrieved after identifying patients with seizures .Children with first episode of unprovoked afebrile seizure in whom EEG and neuroimaging was done were included in the study. 


\section{Shwetha et al; Rale of Electraencephalagram and Neuraimaging in First Afebrile Seizure}

\section{Exclusion criteria:}

Children $<1$ year of age, children previously diagnosed with a seizure disorder/ cerebral palsy / neurological illness , biochemical abnormalities/ head trauma causing seizure were excluded .

Demographic data, detailed history with special regard to type and duration of seizures, significant family history, complete examination including developmental assessment and neurological examination findings were noted .

EEG reports were interpreted by an experienced consultant neurologist and neuroimaging reports were analysed by a single radiologist to eliminate inter observer variation.

Data was analysed using SPSS software version 17.0. A P value $<0.05$ was considered as statistically significant.

The 2017 International League against Epilepsy (ILAE) Classification (Revised) of seizure types was used to classify seizures. ${ }^{[9]}$

\section{Results}

\begin{tabular}{|l|l|l|l|}
\hline Table 1: Demographic data of study subjects & \multirow{2}{*}{ P value } \\
\hline \multirow{2}{*}{ Demographic data } & \multicolumn{2}{|l|}{ Type of seizure } & \\
\cline { 2 - 3 } & Partial & GTCS & \\
\hline Age group & & & 0.01 \\
\hline 1-5 YRS & $7(63.6 \%)$ & $33(61.1 \%)$ & \\
\hline 5-18 YRS & $4(36.4 \%)$ & $21(38.9 \%)$ & \\
\hline Gender & & & 0.08 \\
\hline MALE & $5(45.5 \%)$ & $23(42.6 \%)$ & \\
\hline FEMALE & $6(54.5 \%)$ & $31(57.4 \%)$ & \\
\hline
\end{tabular}

256 children were admitted with seizures to our hospital during the study period, of which 108 children had first episode of unprovoked afebrile seizures .43 children were excluded from the study due to non-availability of EEG and MRI reports. Rest of the 65 children in whom EEG and MRI was done were included in the study. Of the children included in the study 28 were females and 37 were males. 40 children were in the age group of 1-5 years. 54 children $(83.1 \%)$ had GTCS and 11 (16.9\%) had partial seizures, predominantly seen in children less than 5 years of age. [Table 1]

\section{EEG findings:}

EEG abnormalities were seen in 21 out of 65 (32\%) children whereas 44 children had normal EEG. Children with GTCS had significantly higher incidence of EEG abnormalities when compared to children with partial seizures. The most common EEG abnormality observed was sharp and spike wave discharge. [Table $2 \& 3$ ]

\section{MRI findings:}

MRI was normal in $89 \%$ (58) children and abnormal in 10.7

$\%$ (7) children .MRI abnormalities were significantly ( $\mathrm{p}<$ $0.01)$ higher in children with partial seizures (6.15\%) compared to children with GTCS. The MRI findings have been depicted in [Table 4].
Table 2: Seizure type and abnormal EEG pattern

\begin{tabular}{|l|l|l|}
\hline Seizure type & Abnormal EEG & Percentage \\
\hline Focal & 6 & $28.6 \%$ \\
\hline GTCS & 15 & $71.4 \%$ \\
\hline
\end{tabular}

Table 3: EEG findings observed in study group

\begin{tabular}{|l|l|}
\hline EEG Finding & Total \\
\hline Generalised sharp and spike waves & $6(9.18 \%)$ \\
\hline $\begin{array}{l}10 \mathrm{~Hz} \text { alpha activity in posterior head and } \\
\text { bilateral temporal region }\end{array}$ & $1(1.53 \%)$ \\
\hline Bifrontalepileptiform discharges & $1(1.53 \%)$ \\
\hline Periodic lateralised epileptic form discharges & $1(1.53 \%)$ \\
\hline Sharp and slow waves in bifrontal region & $1(1.53 \%)$ \\
\hline $\begin{array}{l}\text { Sharp and slow waves in biparieto-oocipital } \\
\text { region }\end{array}$ & $1(1.53 \%)$ \\
\hline $\begin{array}{l}\text { Spike ,sharp waves bifronto-temporal region } \\
\text { region }\end{array}$ & $3(4.59 \%)$ \\
\hline Sharp waves bifronto-temporal region & $2(3.06 \%)$ \\
\hline Sharp slow in bifrontal & $2(3.06 \%)$ \\
\hline Spike over fronto-temporal & $2(3.07 \%)$ \\
\hline Spike over bifrontocentral region & $1(1.53 \%)$ \\
\hline
\end{tabular}

Table 4: Correlation of EEG and MRI findings
\begin{tabular}{|l|l|l|l|}
\hline EEG & FOCAL & GTCS & p-value \\
\hline Abnormal & $6(9.23 \%)$ & $15(23.07 \%)$ & 0.01 \\
\hline Normal & $5(7.6 \%)$ & $39(60 \%)$ & \\
\hline MRI & & & \\
\hline Abnormal & $4(6.15 \%)$ & $3(4.6 \%)$ & \\
\hline Normal & $7(10.76 \%)$ & $51(78.4 \%)$ & \\
\hline
\end{tabular}

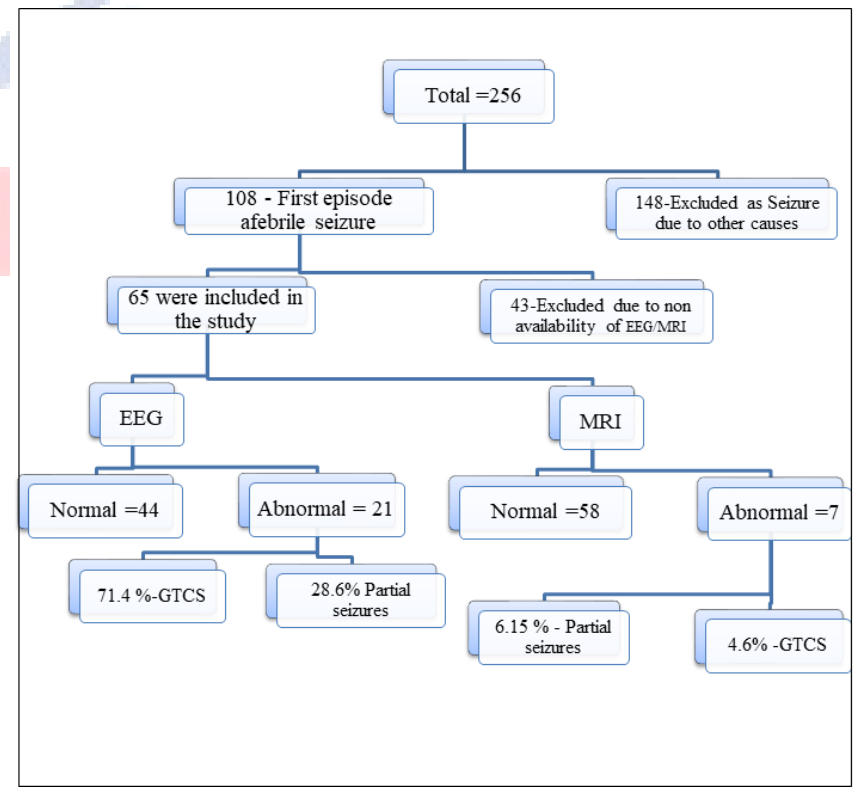

\section{Discussion}

Seizures are one of the most common neurological problems in children .The first episode of seizure is always an anxiety-causing event for parents and it is the health professional's duty to know the best approach and recommendations to use in each case.

In our study we intended to analyse the correlation between a first episode of unprovoked afebrile seizure and the 
occurrence of significant EEG as well as neuroimaging findings.

First unprovoked seizure (FUS) is defined as first nonfebrile seizure that cannot be explained by an immediate, obvious precipitating cause such as head trauma or intracranial infection

EEG is a noninvasive, readily available and inexpensive investigation tool, helps in diagnosis of the event, identification of a specific syndrome, and prediction of longterm outcome. It also helps to differentiate a seizure from other events and predicts the risk for recurrence. ${ }^{[11]}$

American EEG society recommends EEG to be performed after all first non febrile seizures. However optimal timing for obtaining EEG is not clear, EEG done within 24 hours of the seizure is most likely to show background and epileptiform abnormalities. ${ }^{[5,10]}$

EEGs performed for new-onset seizures show epileptiform discharge in approximately $18 \%$ to $56 \%$ of children. ${ }^{[12]}$ In our study, we found that $32.3 \%$ of children had EEG abnormalities. However in a study done by Doescher et al EEG abnormality was observed in $65.7 \%$ of children, ${ }^{[13]}$ a comparatively lower incidence of EEG abnormality noted in our study could be probably due to variable timings and method of EEG recording. Also, sometimes in remote and deep epileptic focus EEG can be normal. ${ }^{[10]}$

In our study overall $71 \%$ patients with generalized seizures had EEG abnormalities which was consistent with similar observations made by Al-Sulaiman et al, ${ }^{[14]}$ and Doose et $\mathrm{al}^{[15]}$ in cases of newly diagnosed seizure.

On analyzing individual abnormalities in EEG, it was observed that the most common abnormality detected was sharp wave and spikes (either alone or both) as observed by studies conducted by Baheti et al16 and Doose et al. ${ }^{[15]}$ However, Shinnar et al, ${ }^{[17,20]}$ Doescher et al, ${ }^{[15]}$ observed a focal slowing as most common EEG abnormality which had predominantly the children with partial seizures.

Neuroimaging can also be useful adjunctive tool in evaluation of a first episode of afebrile seizure but its role in paediatric patients with first episode of unprovoked seizure is still a controversy. MRI is more sensitive than CT and is the modality of choice when indicated. ${ }^{[10]}$

Meta analytic studies done have shown that neuroimaging abnormalities are found in $30 \%$ of children but clinically significant changes were seen in $13 \%$, however it doesn't influence treatment or management decisions on hospitalization.

American academy of neurology recommends emergent neuroimaging only in children who have post ictal focal deficits not resolving quickly and children not returning to baseline within several hours after the seizure. Emergency neuroimaging should be performed in a child with first afebrile seizure to look for intracranial pathologies needing immediate intervention. ${ }^{[5]}$

Non urgent imaging studies with MRI should be considered in child with significant congnitive or motor impairement, focal seizures, unexplained neurological examination, age less than 1 year and EEG that doesn't show benign partial epilepsy or generalized epilepsy of childhood. ${ }^{[5]}$

In our study, MRI abnormalities was seen in $7(10.7 \%)$ children which was consistent with the study done by Sharma et $\mathrm{al}^{[18]}$ where they found that overall incidence of neuroimaging abnormality was $8 \%$, (26\% in high risk children and $2 \%$ in low risk) emphasizing the need of neuroimaging in only high risk category like presence of predisposing conditions and focal seizures in less than 3 years , whereas well appearing and low risk children don't warrant immediate neuroimaging. ${ }^{[18]}$

However, in various studies with children evaluated for first episode of unprovoked seizures prevalence of abnormalities in the neuroimaging ranged from $0-21 \%^{[19]}$ probably due to inclusion of non significant MRI findings as well.

Limitations of our study were small sample size, as it was retrospective study casual relationship between investigation findings and clinical condition of the patient couldn't be obtained, further studies are needed to establish the role of neuroimaging in Paediatric age group.

\section{Conclusion}

EEG is a highly useful tool in evaluating all children with first episode of unprovoked seizure.

However neuroimaging with MRI is not routinely indicated in all well appearing children with afebrile seizures and should be reserved only for high risk category.

\section{Acknowledgment:}

We thank all those who have helped to make this research possible, especially the children, the parents, and the families. Special thanks to Dr.Sahana ,Dr.Poorvi and Dr.Shrishail for their invaluable support .We also thank the Staff of department of paediatrics , A J Institute of medical sciences, Mangalore who were involved in the care of these children.

\section{References}

1. Hauser WA, Rich SS, Annegers JF, Anderson VE. Seizure recurrence after a $1^{\text {st }}$ unprovoked seizure: an extended follow-up. Neurology 1990;40:1163-70.

2. Hauser WA, Annegers JF, Rocca WA. Descriptive epidemiology of epilepsy: contributions of population-based studies from Rochester, Minnesota. MayoClinProc 1996;71(6):576-86.

3. Pallin DJ, Goldstein JN, Moussally JS, Pelletier AJ, Green AR, Camargo Jr. CA. Seizure visits in US emergency departments: epidemiology and potentialdisparities in care. Int $\mathrm{J}$ Emerg Med 2008;1(2):97-105.

4. Pohlmann-Eden B, Beghi E, Camfield C, Camfield P. The first seizure and its management in adults and children.BMJ. 2006;332:339-42

5. Hirtz D, Ashwal S, Berg A, Bettis D, Camfield C, Camfield P, et al Practice parameter: Evaluating a first nonfebrile seizure in children: Report of the quality standards subcommittee of the American 


\section{Shuetha et al; Rale of Electraencephalagram and Neuraimaging in First Afelerile Seizure}

Academy of Neurology, the Child Neurology Society, and the American Epilepsy Society. Neurology. 2000;55:616-23

6. Schoenenberger RA, Heim SM. Indication for computed tomography for brain in patients with firstuncomplicated generalized seizure. BMJ. 1994;309:986-9. [PMC free article] [PubMed]

7. Ramirez-Lassepas M, Cipolle RJ, Morillo LR, Gumnit RJ. Rate of computed tomographic scan in the evaluation of adult patients after their first seizure. Ann Neurol. 1984;15:536-43.

8. Simone CV, Paulo Breno NL, Monica JS, Adriana BO, Alaides SFO, Alfredo LJ. First unprovokedseizure: Clinical and electrographic aspects. J Epilepsy ClinNeurophysiol. 2006;12:69-72

9. ILAE classification of epilepsies (2017) Revised classification https://www.epilepsy.com/article/2016/12/2017

10. Guidelines for Diagnosis and Management of Childhood Epilepsy Expert committee on pediatric epilepsy, Indian paediatrics, volume 46_august 17, 2009

11. Jaya shankar kaushik, Rajni farmania : Electroencephalography in pediatric epilepsy, Indian paediatrics volume 55_october 15, 2018

12. Elaine C. Wirrell Prognostic Significance of Interictal Epileptiform Discharges inNewly Diagnosed Seizure Disorders. (J Clin Neurophysiol 2010;27: 239-248)

13. Doescher JS, deGrauw TJ, Musick BS, Dunn DW, Kalnin AJ, Egelhoff JC, et al. Magneticresonance imaging and electroencephalographic findings in a cohort of normal children with newlydiagnosed seizures. J Child Neurol. 2006;21:491-5

14. Al-Sulaiman AA, Ismail HM. Clinical pattern of newly diagnosed seizure in Saudi Arabia: A prospective study of 263 children. Childs Nerv Syst. 1999;15:468-71

15. Doose $\mathrm{H}$, Lunale $\mathrm{H}$, Castiglione $\mathrm{E}$, Waltz S. Severe idiopathic generalized epilepsy of infancy. Neuropediatrics. 1998;29:229-38

16. Baheti R, Gupta BR, Baheti R. A study of CT and EEG findings in patients with generalized or partial seizures in western Rajasthan. J Indian AcadClin Med. 2003;4:25-9.

17. Shinnar S, Kang H, Berg AT, Goldensohn ES, Hauser WA, Moshé SL. EEG abnormalities inchildren with a first unprovoked seizure. Epilepsia. 1994;35:471-6

18. Sharma S, Riviello JJ, Harper MB, Baskin MN. The role of emergent neuroimaging in children with new-onset afebrile seizures. Pediatrics 2003;111 (1):1-5

19. R. Al-shamiA.M. Khaira M.K.IbrahimaElseidaet al. Neuro-imaging evaluation after the first afebrile seizure in children: A retrospective observational study Seizure 43 (2016) 26-31

20. Shinnar Shlomo, O’Dell Christine, Mitnick Robin, Berg Anee T, Moshe Solomon L. Neuroimaging abnormalities in children with an apparent first unprovoked seizure. Epilepsy Res. 2001;43:261-9.

Copyright: (c) the author(s), 2019. It is an open-access article distributed under the terms of the Creative Commons Attribution License (CC BY 4.0), which permits authors to retain ownership of the copyright for their content, and allow anyone to download, reuse, reprint, modify, distribute and/or copy the content as long as the original authors and source are cited.

How to cite this article: Shwetha G, Bhat S, Soans ST. Role of Electroencephalogram and Neuroimaging in First Afebrile Seizure in Children: A Retrospective Study. Asian J. Clin. Pediatr. Neonatol.2019;7(1):51-54.

DOI: dx.doi.org/10.21276/ajcpn.2019.7.1.12

Source of Support: Nil, Conflict of Interest: None declared. 